\title{
Evaluation of Prognostic Factors and Survival Results in Pediatric Hodgkin's Lymphoma-single center experience from Eastern Black Sea Region of Turkey
}

\author{
Kandaz M*, Güler OC, Memiş Y, Bahat Z, Canyılmaz E, and Yöney A
}

Karadeniz Technical University, Faculty of Medicine, Department of Radiation Oncology, Turkey

${ }^{*}$ Corresponding author: Kandaz M, Karadeniz Technical University Faculty of Medicine Department of Radiation Oncology, Trabzon/Turkey, Tel: 04623775595, E-mail: mkandaz61@gmail.com

Citation: Kandaz M, Güler OC, Memiş Y, Bahat Z, Canyılmaz E, et al. (2017) Evaluation of Prognostic Factors and Survival Results in Pediatric Hodgkin's Lymphoma-single center experience from Eastern Black Sea Region of Turkey. J Hematol Blood Disord 3(1): 101. doi: 10.15744/2455-7641.3.101

Received Date: January 18, 2017 Accepted Date: August 15, 2017 Published Date: August 17, 2017

\begin{abstract}
Objective: Study clinical features and treatment results of Pediatric Hodgkin's Lymphoma patients and investigate prognostic factors affecting survival.

Materials and Methods: Data of 44 Hodgkin's Lymphoma patients (15 females, 29 males) below 16 years of age [mean age $10.4 \pm 4.2$ (3-16)] treated and monitored in our institution between 1996 and 2015 was studied retrospectively.

Results: $50 \%$ of the patients had early stage (stage I-II) of the disease. The most common histological type was mixed cellular Hodgkin's lymphoma (MCHL). All patients received chemotherapy. After chemotherapy, involved field radiotherapy was administered to all patients. Median survival time was $164.32 \pm 13.8$ months and 1-, 3-, 5- and 10-year survival rates were $96 \%, 91.8 \%, 88.3 \%$ and $\% 87.9$, respectively. In univariate analysis, stage $(\mathrm{p}<0.005)$ and ECOG performance score $(\mathrm{p}<0.0001)$ were found to be variables with effects on overall survival. In multivariate analysis, only ECOG performance score $(\mathrm{p}<0.003)$ was found to be statistically significant.

Conclusion: Although our treatment results are similar to those of other treatment centers, we will be able to contribute more to clinical features and treatment results of pediatric Hodgkin's lymphoma patients, with higher number of patients.
\end{abstract}

Keywords: Pediatric Hodgkin's lymphoma; Patient's characteristics; Chemotherapy; Radiotherapy; Prognostic factors; Survival

\section{Introduction}

Hodgkin's lymphoma constitutes $1 \%$ of all cancers and 25 to $40 \%$ of lymphomas [1]. Lymphomas comprise $25 \%$ of childhood cancers and they are the second most common group of cancer after leukemias. It peaks twice with one at the second decade and one at the fifth decade [2]. It is observed at an early age especially in developing countries, however, it is observed after 55 years of age in developed countries. Its incidence at an early age is also high in Turkey [2,3]. Its incidence below 15 years of age is 5-7/1000000. In its etiology, autoimmune factors, genetic, and certain virus (such as EBV) infections are held responsible [4].

Among oncological diseases, Hodgkin's lymphoma has a high cure rate. Overall survival and disease-free survival rates have increased considerably especially in recent years by combined use of chemotherapy (CT) and radiotherapy (RT) in the treatment protocol.

The aim of this study was to determine the outcomes of our patients who presented with favorable risk early-stage Hodgkin lymphoma, unfavorable risk early-stage Hodgkin lymphoma and advanced stage Hodgkin lymphoma that were treated either with chemotherapy plus radiotherapy and prognostic factors affecting treatment response and survival.

\section{Materials and Methods}

Data of 44 Hodgkin's Lymphoma patients aged $\geq 3-\leq 16$ years diagnosed, treated and currently on follow-up in our institution between 1996 and 2015 was studied retrospectively. From patient files; sex, age, complaints, histology, stage, region of involvement of lymph node, presence of B symptoms ( fever $>38{ }^{\circ} \mathrm{C}$, night sweats, and more than $10 \%$ weight loss in the last six months), whether there is any extranodal involvement, splenic involvement and bone marrow involvement or not were all noted. Eastern Cooperative Oncology Group (ECOG) scale was used for performance status of the patients. Cotswolds Modification of Ann Arbor staging system was applied during staging. In addition, patients were classified into early stage (stage I-II) favorable group (favorable factors for stage I-II disease: no bulky mediastinal or $<10 \mathrm{~cm}$ disease, erythrocyte sedimentation rate $($ ESR) $<50, \leq 3$ 
sites of disease), early-stage (stage I-II ) unfavorable group (unfavorable factors for stage I-II disease: bulky mediastinal or $\geq 10 \mathrm{~cm}$ disease, B symptoms, ESR $>50,>3$ sites of disease) and advanced stage (stage III-IV) disease according to risk factors, including whether a patient has bulky disease, extranodal involvement, high sedimentation (if the patient has B symptom, $\geq 30$; if not, $\geq 50$ ) and $\geq 3$ involved areas. The presence of lymphadenopathy that was $1 / 3$ greater than the widest intrathoracic diameter on the T5-6 level in plain lung radiography and peripheral lymphadenopathy whose largest diameter was $\geq 5 \mathrm{~cm}$ were considered to be bulky disease. The patients' hemoglobin (Hb), ESR and lactate dehydrogenase (LDH) levels were recorded at the time of first admission. Applied treatments (chemotherapy, radiation therapy and bone marrow transplantation) were recorded. Treatment responses were evaluated by using imaging modalities as Computerized tomography and PET-CT, where appropriate.

All patients received ABVD (Adriamycin ( $25 \mathrm{mg} / \mathrm{m}^{2}$ on 1 st and 15th days), Bleomycin (10 mg/ $\mathrm{m}^{2}$ on $1 \mathrm{st}$ and 15 th days), Vinblastine $\left(6 \mathrm{mg} / \mathrm{m}^{2}\right.$ on $1 \mathrm{st}$ and 15 th days) or Vincristine $\left(1.5 \mathrm{mg} / \mathrm{m}^{2}\right.$ on 1 st and 15 th days), Dacarbazine ( $375 \mathrm{mg} / \mathrm{m}^{2}$, on $1 \mathrm{st}$ and 15 th days)) protocol as CT (18 patients (41\%) received 2 doses, 18 patients (\%41) 4 doses, and 8 patients (\%18) 6 doses).

RT (15-41.4 Gy) was administered to 44 patients after CT. The 3 dimensional conformal radiotherapy (3DRT) techniques were used. The clinical target volume (CTV): the area where the lymphoma is located including adjacent lymph nodes before chemotherapy, The planned target volume (PTV) was forged with $1.5 \mathrm{~cm}$ margins given to the CTV. Daily fractions of 150, 180 and 200 cGy were used during RT. A dose of $1500 \mathrm{cGy}$ was administered after CT, if full response is received from children less than 5 years of age, an average dose of $2000 \mathrm{cGy}$ in the case of children less than 10 years of age with full response, and a dose of $2500 \mathrm{cGy}$ in the case of those with partial response. Doses of 2500-3000 cGy were used in patients above 10 years of age with full response and doses of 3600-4140 cGy with boost in the case of those with partial response. Properties of RT area are given in Table 1. Briefly, mantle and mini mantle treatment portals account for half of the patients while IFRT was given in $30 \%$ of patients. IFRT encompasses a region, not an individual LN. Extended RT fields encompasses mini-mantle (bilateral cervical, SCF, infraclavicular, axilla), mantle (bilateral cervical, SCF, infraclavicular, mediastinal, hilar, axilla) and inverted Y (paraaortic, bilateral pelvic and inguino-femoral \pm splenic).

\begin{tabular}{|c|c|c|}
\hline & $\mathbf{n}$ & $\%$ \\
\hline IFRT & 13 & 30 \\
\hline Neck+SCF & 4 & 9 \\
\hline Mini- Mantle & 7 & 16 \\
\hline Mantle & 15 & 34 \\
\hline Mantle+İnverted Y & 5 & 11 \\
\hline
\end{tabular}

IFRT: involved-field radiotherapy, SCF:Supraclavicular fossa, Mini-mantle: Bilateral cervical, SCF, infraclavicular, axilla, Mantle: Bilateral cervical, SCF, infraclavicular, mediastinal, hilar, axilla, İnverted Y: Paraaortic, bilateral pelvic and inguino-femoral \pm splenic

Table 1: Properties of RT Area

During follow-up of patients, complete response, partial response and progression were assessed. In addition, relapse treatment and outcomes were recorded. The data obtained was uploaded to SPSS 13.0 software. Kaplan- Meier test was used for survival time. Prognostic factors were calculated by long- rank test. Cox regression analysis was used for multivariate analysis. $\mathrm{P}<0.05$ was considered significant.

\section{Results}

A total of 44 patients, 29 of which (66\%) were male, 15 of which (34\%) were female, were included in the study. Mean age was 10.4 $\pm 4.2(3-16) .69 \%$ of the patients were at the age of 10 years and above.

Their distribution by stage was as follows: 2 patient (5\%) in stage $1 \mathrm{~A} ; 15$ patients (34\%) in stage $2 \mathrm{~A}, 6$ patient (13\%) in stage $2 \mathrm{~B}, 3$ patient $(7 \%)$ in stage 2 S, 1 patients (2\%) in stage $3 \mathrm{~A}, 8$ patients (19\%) in stage $3 \mathrm{~B}, 4(9 \%)$ in stage $3 \mathrm{~S}$ and 5 patients (11\%) in stage IV (Stage I $5 \%$, stage II $54 \%$, stage III $30 \%$, stage IV $11 \%$ ). If the patients are rated by risk factors, 22 patients (50\%) were in early stage favorable group, 4 patients (9\%) were in early stage unfavorable group and 18 patients (41\%) were in advanced stage.

According to the histological type, 9 patients (20\%) were lymphocyte-predominant HL (LRHL), 15 (35\%) were nodular sclerosing HL (NSHL) and 20 (45\%) were mixed type HL (MCHL). At the time of diagnosis, 89\% of the patients had an ECOG performance score of 0 and 1 and $32 \%$ had B symptom and $11 \%$ had Bulky disease. 7 patients (16\%) had spleen involvement. Patient's demographic characteristics and clinical data are shown in Table 2.

During follow-up, 4 patients (\%9) relapsed (8-22 months). Patients who relapsed were given a 2. series of CT (COPP/OEPA), 1 patient received RT after CT, and the other 3 patients were monitored.

Median survival time was $164.32 \pm 13.8$ months in our patients with $168.4 \pm 12.9$ months for males and $106.8 \pm 14.7$ months for females. 1, 3, 5 and 10 year overall survival rates were $96 \%, 91.8 \%, 88.3 \%$ and $\% 87.9$, respectively (Figure 1). According to risk groups, $1,3,5$ and 10 year survival rates for early favorable group were $100 \%, 100 \%, 100 \%$ and $100 \%$, respectively, early unfavorable group $98.8 \%, 93.5 \%, 88.1 \%$ and $80.2 \%$ respectively and for advanced stage $90.2 \%, 87.9 \%, 71.9 \%$ and $71.9 \%$, respectively. 


\begin{tabular}{|c|c|c|}
\hline & n & $\%$ \\
\hline Female/Male & $15 / 29$ & $34 / 66$ \\
\hline Age & \multicolumn{2}{|c|}{$10.4 \pm 4.2$} \\
\hline \multicolumn{3}{|c|}{ Histology } \\
\hline LRHL & 9 & 20 \\
\hline NSHL & 15 & 35 \\
\hline MCHL & 20 & 45 \\
\hline B symptom & 14 & 32 \\
\hline Bulky & 5 & 11 \\
\hline Spleen involvement & 7 & 16 \\
\hline \multicolumn{3}{|c|}{ Stage } \\
\hline I & 2 & 5 \\
\hline II & 24 & 54 \\
\hline III & 13 & 30 \\
\hline IV & 5 & 11 \\
\hline $\begin{array}{l}\text { Early stage } \\
\text { favorable }\end{array}$ & 22 & 50 \\
\hline $\begin{array}{l}\text { Early stage } \\
\text { unfavorable }\end{array}$ & 4 & 9 \\
\hline Advanced stage & 18 & 41 \\
\hline ECOG 0 & 27 & 62 \\
\hline ECOG 1 & 12 & 27 \\
\hline ECOG 2 & 4 & 9 \\
\hline ECOG 3 & 1 & 2 \\
\hline \multicolumn{3}{|c|}{ Latest status } \\
\hline Alive/Dead & $39 / 5$ & $89 / 11$ \\
\hline
\end{tabular}

LRHL: Lymphocyte-predominant HL, NSHL: Nodular sclerosing HL, MCHL: Mixed type HL Table 2: Pediatric HL patient's characteristics

Survival Function

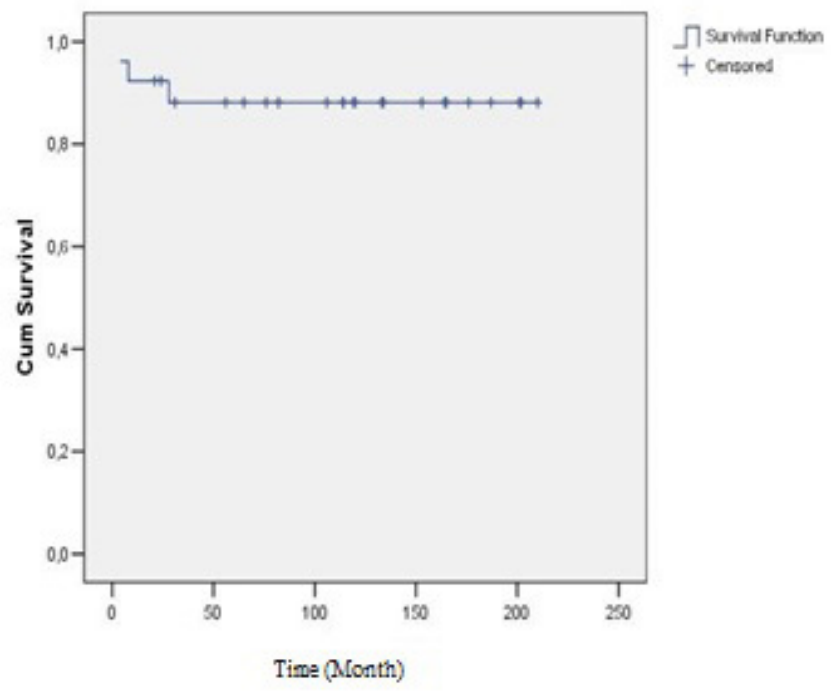

Figure 1. Overall survival

Several prognostic factors have been identified for Hodgkin's lymphoma. These are age, sex, B symptom, bulky disease, ECOG performance score and stage. In our study, age, sex, stage, histology, ECOG performance score, presence of symptom B and presence of bulky disease were evaluated. In univariate analysis, stage $(p<0.005)$ and ECOG performance $s c 0 r e(p<0.0001)$ were found to be variables with effects on overall survival. In multivariate analysis, only ECOG performance score ( $\mathrm{p}<0.003$ ) was found to be statistically significant. In Table 3 , p values of prognostic factors are shown. 


\begin{tabular}{|c|c|c|}
\hline \multirow{2}{*}{ Variable } & \multicolumn{2}{|c|}{$\mathbf{p}$} \\
\cline { 2 - 3 } & Univariate & Multivariate \\
\hline Age & 0.235 & \\
\hline Sex & 0.698 & \\
\hline Stage & 0.005 & \\
\hline Risk factors & 0.108 & \\
\hline Histology & 0.546 & \\
\hline ECOG status & 0.0001 & 0.003 \\
\hline B symptom & 0.006 & \\
\hline Bulky & 0.342 & \\
\hline Relapse & 0.511 & \\
\hline
\end{tabular}

Table 3: Prognostic Factors

\section{Discussion}

Pediatric Hodgkin's lymphoma patients on follow-up in our clinic were studied retrospectively; efforts were placed on identifying their epidemiological and clinical features; success of the treatment applied and prognostic factors affecting survival were set forth.

Hodgkin's lymphoma peaks twice with one around the age of 20, and the other around the age of 45 [1]. Its incidence before the age of 20 is high in developing countries, whereas it develops in later years in developed countries. Its incidence gradually increases after the age of 10 especially in developing countries depending on socio-economic reasons, and peaks at the age of 20 something. The problem is excessive industrialization in developed countries [5]. Although previous research reported a mean age at diagnosis of 7-8 years in Turkey, mean age at diagnosis of our patients was $10[2,3,6]$.

In all age groups, it is more common in males. In our patients, male/female ration was $3 / 1$. The most common types are mixed type and nodular sclerosing Hodgkin's lymphoma [5]. In our study, the most common type was mixed type for both sexes.

In Hodgkin's lymphoma, the disease usually occurs in peripheral lymph nodes (LAP) with painless growth at a rate of $90 \%$. It is mostly seen in the cervical region. It has an elastic consistency and is painless. Also in the case of our patients, it developed with peripheral LAP at a rate of $92 \%$.

Prevalence of B symptom varies in the range of 25 to $40 \%$ [7]. 31\% of our patients had B symptom at the time of diagnosis.

In the literature, Hodgkin's lymphoma is most often seen in the early stages, and in our study, $58 \%$ of patients were in the early stage.

Standard treatment for early-stage Hodgkin's lymphoma involves CT (ABVD, MOPP, BEACOPP and Stanford V regimen) and IFRT. 44 of our patients received RT after CT (ABVD).

Possibility of developing secondary malignancy after treatment of Hodgkin's lymphoma is on the increase. Leukemias may develop during the first five years, solid tumors with a majority of soft tissue sarcomas, thyroid, bone and breast cancers may emerge after 15 to 20 years $[8,9]$. No secondary tumor has been detected in our patients yet.

Previous studies reported the overall survival is $97 \%$ and the 3 -year overall survival rates were $88 \%$ and 5 -year overall survival rates were $88 \%$ [10,11]. Mean survival time and overall survival rates in our study were found to be comparable with literature.

There are many articles demonstrating that age, sex, B symptom, bulky disease, ECOG performance score and stage have prognostic importance in Hodgkin's lymphoma [7]. Consistent with literature, stage and ECOG performance score in our study were statistically significant.

In conclusion, both epidemiological and post-treatment survival rates of our pediatric Hodgkin's lymphoma patients were consistent with the literature. However, further information about survival and incidence of secondary cancers can be obtained with increasing number of patients and time of follow-up.

\section{References}

1. Rosen PJ, Lavey RS, Haskell CM (1995) Hodgkin’s Disease In: Haskell CM (ed). Cancer treatment (4th edition) Philadelphia. WB Saunder Company 951-79.

2. Oguz A, Karadeniz C, Okur FV, Citak EC, Pinarli FG, et al. (2005) Prognostic factors and treatment outcome in childhood Hodgkin disease. Pediatr Blood Cancer 45: 670-5.

3. Büyükpamukçu M, Atahan L, Cağlar M, Kutluk T, Akyüz C, et al. (1999) Hodgkin's disease in Turkish children: clinical characteristics and treatment results of 210 patients. Pediatr Hematol Oncol 16: 119- 29.

4. Lanzkowsky P (2011) Manual of pediatric hematology and oncology (5th edition) Burlington, MA: Academic Press 599-623.

5. Thomas RK, Re D, Zander T, Wolf J, Diehl V (2002) Epidemiology and etiology of Hodgkin’s lymphoma. Ann Oncol 13: 147-52. 
6. Cavdar AO, Pamir A, Gözdaşoglu S, Babacan E, Yavuz G, et al. (1999) Hodgkin disease in children: clinicoepidemiologic and viral (Epstein-Barr virus) analyses. Med Pediatr Oncol 32: 18-24.

7. Kelly KM, Hodgson D, Appel B, Chen L, Cole PD, et al. (2013) Children's Oncology Group's 2013 Blueprint for research: Hodgkin Lymphoma. Pediatr Blood Cancer 60: 972-8.

8. Hudson MM, Onciu M, Donaldson SS (2005) Hodgkin lymphoma. In: Pizzo PA, Poplack DG, editors. Principles and practice of pediatric oncology (5th edition) Philedelphia: Lippincott Williams\&Wilkins 694-721.

9. Herbertson R, Hancock BW (2005) Hodgkin Lymphoma in adolescents. Cancer Treat Rev 31: 339-60.

10. Rühl U, Albrecht M, Dieckmann K, et al. (2001) Responseadapted radiotherapy in the treatment of pediatric Hodgkin's disease: an interim report at 5 years of the German GPOH-HD 95 trial. Int J Radiat Oncol Biol Phys 51: 1209-18.

11. Büyükkapu-Bay S, Çorapçığlu F, Aksu G, Anık Y, Demir H, et al. (2015) Prognostic factors and treatment results of pediatric Hodgkin's lymphoma: A single center experience. Turk J Pediatr 57: 359-66.

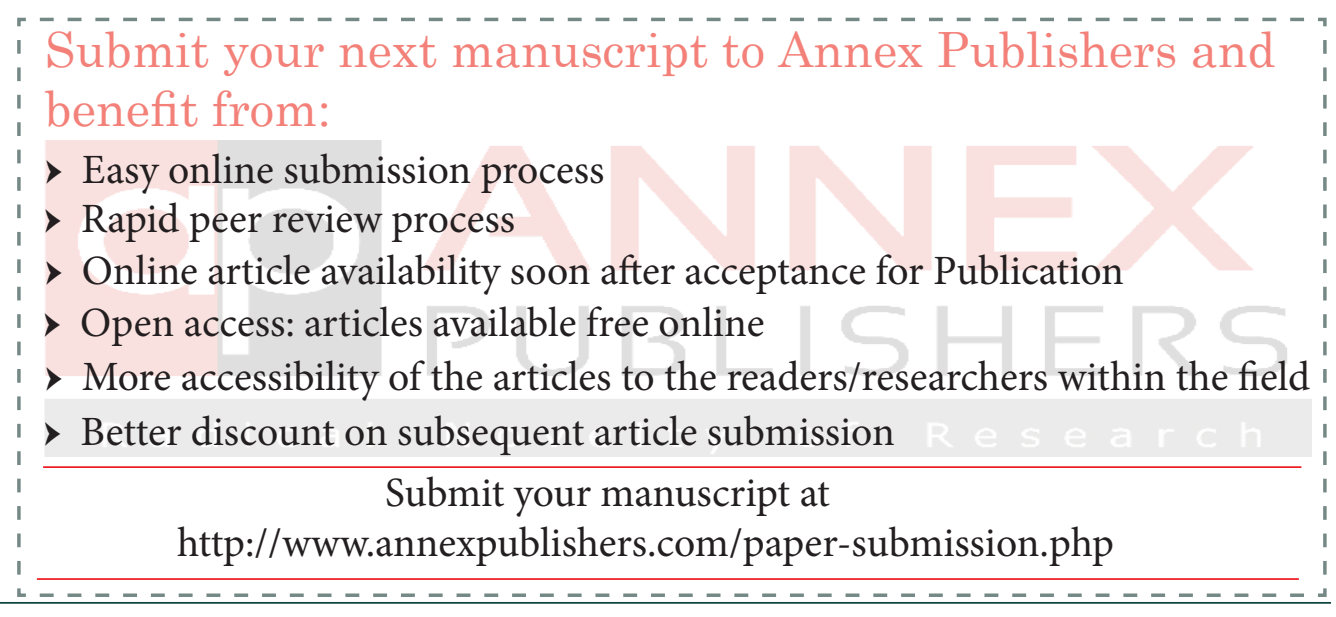

